\title{
Nanowire/Nanotube Array Tandem Cells for Overall Solar Neutral Water Splitting
}

Alireza Kargar, ${ }^{1}$ Jirapon Khamwannah, ${ }^{2}$ Chin-Hung Liu, ${ }^{2}$ Namseok Park, ${ }^{1}$ Deli Wang, ${ }^{1,2,4}$ "Shadi A. Dayeh, ${ }^{1}$ Sungho Jin, ${ }^{2,3 *}$

${ }^{1}$ Department of Electrical and Computer Engineering, University of California-San Diego, 9500 Gilman Drive, La Jolla, California 92093, United States

${ }^{2}$ Materials Science and Engineering Program, University of California-San Diego, 9500 Gilman Drive, La Jolla, California 92093, United States

${ }^{3}$ Department of Mechanical and Aerospace Engineering, University of California-San Diego, 9500 Gilman Drive, La Jolla, California 92093, United States ${ }^{4}$ Qualcomm Institute (QI), University of California-San Diego 9500 Gilman Drive, La Jolla, California 92093, United States

*Corresponding authors: jin@ucsd.edu, d.w.wang@ieee.org 
ABSTRACT: In this study, we report the fabrication and characterization of a novel PEC tandem cell, consisting of $\mathrm{p}-\mathrm{Si} / \mathrm{TiO}_{2} / \mathrm{Fe}_{2} \mathrm{O}_{3}$ core/shell/hierarchical nanowire (csh-NW) array photocathode and $\mathrm{TiO}_{2} / \mathrm{TiO}_{2}$ core/shell nanotube (cs-NT) array photoanode, for overall solar water splitting in a neutral $\mathrm{pH}$ water. The $\mathrm{p}-\mathrm{Si} / \mathrm{n}-\mathrm{TiO}_{2} / \mathrm{n}-\mathrm{Fe}_{2} \mathrm{O}_{3}$ csh-NWs, made mainly by solution-processed methods, offer significantly improved performance in the neutral $\mathrm{pH}$ water with a low (positive) onset potential and photoactivity at zero bias, due to the increased reaction surface area, effective energy band alignment among p-Si, n- $\mathrm{TiO}_{2}$ and $\mathrm{n}-\mathrm{Fe}_{2} \mathrm{O}_{3}$ enhancing the charge separation, improved optical absorption, and enhanced gas evolution. Nitrogen modification (annealing under $\mathrm{N}_{2}$ ) is used to further enhance the csh-NWs photocathodic performance. The PEC tandem cell is then able to handle overall solar water splitting in the neutral $\mathrm{pH}$ water with a solar-to-hydrogen (STH) efficiency of $\sim 0.18 \%$. The achieved results

demonstrate initial steps toward the realization of full PEC devices using earth-abundant materials for solar hydrogen generation suggesting competitive performance when solar matched photoanode core material and co-catalysts are used.

Keywords: core/shell/hierarchical nanowires (csh-NWs), core/shell nanotubes (cs-NTs), photoelectrochemical (PEC) tandem cell, overall solar water splitting, neutral $\mathrm{pH}$ water.

\section{Introduction}

Photoelectrochemical (PEC) hydrogen production through solar water splitting is considered as a promising approach for clean hydrogen fuel generation [1-8], which has potential for high solar-to-hydrogen (STH) efficiencies of over 30\% [9]. Obtaining a PEC tandem cell (full PEC 
device/system) in a Z-scheme configuration to handle efficient and durable overall spontaneous solar water splitting is challenging. Its key difficulties remain in the design and engineering of efficient and stable photoelectrodes (photocathode and photoanode) using earth-abundant materials with cost-effective, simple, and scalable fabrication processes without co-integration of photovoltaic/catalysts cells or the use of conventional metal counter electrodes [10]. To run overall solar water splitting in a full PEC device, both individual photocathode and photoanode should provide a low onset potential in one specific electrolyte in a way that their photocurrents cross each other [1]. There has been tremendous progress on individual photoelectrodes with high cathodic or anodic performances [2, 7, 11-24], however, coupling of most of such photoelectrodes to build a PEC tandem cell has been difficult due to some limitations such as operation of photoelectrodes in different electrolytes, high onset potentials that prevent the crossing of photocurrents, etc. Indeed, Mor et al. have demonstrated metal oxide nanotube arrays for self-biased hydrogen generation cell, in which the correspondent photocathode and photoanode were immersed in $0.1 \mathrm{M} \mathrm{Na}_{2} \mathrm{HPO}_{4}$ and $1 \mathrm{M} \mathrm{KOH}$, respectively, achieving a photoconversion efficiency of $0.30 \%$ [25].

Si/metal-oxide heterojunction electrodes have shown promising PEC performances for both cathodic and anodic conditions exhibiting potential to reduce their onset potential to the desirable values $[18,26-32]$. For example for the $\mathrm{Si} / \mathrm{Fe}_{2} \mathrm{O}_{3}$ electrodes, Mayer et al. have shown the reduction of photoanodic turn-on potential through the dual-absorber nature of the n-Si/n- $\mathrm{Fe}_{2} \mathrm{O}_{3}$ junction [18], while Jun et al. have reported the photoanodic onset potential decrease due to the catalytic effect of $n-\mathrm{Fe}_{2} \mathrm{O}_{3}$ on $\mathrm{n}-\mathrm{Si}$ [33]. Building full PEC systems based on nanowire (NW) heterojunction photoelectrodes is a promising approach for solar hydrogen production due to unique characteristics of NWs, facile NW fabrication methods, ability to form different NW 
heterostructures, etc. Liu et al. have reported an integrated system of catalyst-loaded $\mathrm{Si}$ and $\mathrm{TiO}_{2}$ NWs for direct solar water splitting achieving a $0.12 \%$ solar-to-fuel efficiency in $0.5 \mathrm{M} \mathrm{H}_{2} \mathrm{SO}_{4}$ solution [4]. On the other hand, having a PEC tandem cell working in neutral $\mathrm{pH}$ water is highly desirable as the natural water resources such as seawater are usually in a neutral condition, and are abundant and easily disposable. Employing a neutral electrolyte for solar water splitting also prevents the undesirable use of strong acids or bases, which can lead to environmental and handling issues.

In this paper, we demonstrate a novel PEC tandem cell, consisting of p-Si/ $/ \mathrm{TiO}_{2} / \mathrm{Fe}_{2} \mathrm{O}_{3}$ core/shell/hierarchical nanowire (csh-NW) array photocathode and $\mathrm{TiO}_{2} / \mathrm{TiO}_{2}$ core/shell nanotube (cs-NT) array photoanode, for overall solar water splitting in a neutral $\mathrm{pH}$ water. The csh-NWs, made mainly by solution-processed methods, provide considerably enhanced performance in the neutral $\mathrm{pH}$ water with a low (positive) onset potential and photoactivity at zero bias. The csh-NWs photocathodic performance is further improved using nitrogen modification. The cs-NTs also offer improved performance. The mechanism of performance improvement for the photoelectrodes is studied. The PEC tandem cell is able to drive overall solar neutral water splitting with a STH efficiency of $\sim 0.18 \%$.

\section{Experimental Section}

\subsection{Fabrication of $\mathrm{p}-\mathrm{Si} / \mathrm{TiO}_{2} / \mathrm{Fe}_{2} \mathrm{O}_{3} \mathrm{csh}-\mathrm{NWs}$ photocathodes}

Wafer-scale vertically ordered Si NW arrays on p-type boron-doped Si(100) wafers with resistivity of 1-20 $\Omega \mathrm{cm}$ were achieved using an aqueous Ag-assisted electroless etching technique [34]. The etching time was 20 mins resulting in a NW length of $\sim 6.5 \mu \mathrm{m}$. The etched Si NW samples were then dipped into buffered oxide etch (BOE) solution for $10 \mathrm{sec}$ to remove 
the native oxide layer, rinsed with deionized (DI) water, dried with $\mathrm{N}_{2}$ gas, and transferred to atomic layer deposition (ALD) chamber (Beneq TFS 200). A thin $\mathrm{TiO}_{2}$ shell, working as a seeding layer for the $\mathrm{Fe}_{2} \mathrm{O}_{3}$ nanorods (NRs) growth, was then deposited on the Si NW substrates using ALD deposition in thermal mode (thermal ALD) at a temperature of $250^{\circ} \mathrm{C}$. The number of cycles was 568 giving a thickness of $\sim 25 \mathrm{~nm}$ on flat Si substrate based on a growth rate of $0.44 \AA$ /cycle on $\mathrm{Si}(100)$ film substrate. The $\mathrm{Fe}_{2} \mathrm{O}_{3} \mathrm{NRs}$ were finally grown on the $\mathrm{TiO}_{2}$-coated $\mathrm{Si}$ NW trunks using a hydrothermal growth technique $[35,36]$. Briefly, akaganeite $(\beta-\mathrm{FeOOH}) \mathrm{NRs}$ were first grown on the $\mathrm{TiO}_{2}$-coated $\mathrm{Si} \mathrm{NW}$ cores by immersing the sample in a $45 \mathrm{~mL}$ sealed Teflon autoclave containing a $30 \mathrm{~mL}$ aqueous solution consisting of $0.15 \mathrm{M} \mathrm{FeCl} \cdot 6 \mathrm{H}_{2} \mathrm{O}$ (Iron(III) chloride hexahydrate) (Sigma-Aldrich, $\geq 99 \%$ ) and $1 \mathrm{M} \mathrm{NaNO}_{3}$ (sodium nitrate) (Sigma-Aldrich, $\geq 99.0 \%$ ). The DI water resistivity and solution $\mathrm{pH}$ were 17.6-17.7 M $\Omega$-cm and $\sim 1.44$, respectively. The hydrothermal reaction was carried out at a temperature of $\sim 106^{\circ} \mathrm{C}$ for 3 hrs. The sample was then rinsed cautiously with DI water to remove the residues and dried with $\mathrm{N}_{2}$ gas. Lastly, the $\mathrm{Si} / \mathrm{TiO}_{2} / \mathrm{FeOOH}$ csh-NWs substrates were annealed at $450^{\circ} \mathrm{C}$ in air (denoted as $\mathrm{Si} / \mathrm{TiO}_{2} / \mathrm{A}-\mathrm{Fe}_{2} \mathrm{O}_{3}$ csh-NWs) or under $\mathrm{N}_{2}$ atmosphere (denoted as $\mathrm{Si} / \mathrm{TiO}_{2} / \mathrm{N}-\mathrm{Fe}_{2} \mathrm{O}_{3}$ csh-NWs) for $1 \mathrm{hr}$. The $\mathrm{N}_{2}$ flow during the annealing was $1000 \mathrm{scc} / \mathrm{min}$. The growth of $\mathrm{A}-\mathrm{Fe}_{2} \mathrm{O}_{3}$ and $\mathrm{N}-$ $\mathrm{Fe}_{2} \mathrm{O}_{3}$ NRs on fluorine-doped tin oxide (FTO) substrates was also performed in the same way as that mentioned for the csh-NWs samples. Before the growth, the FTO substrate was cleaned consecutively by sonication in acetone, isopropanol, and DI water for 5 mins each and finally rinsed with DI water and dried with $\mathrm{N}_{2}$ flow. 


\subsection{Fabrication of $\mathrm{p}-\mathrm{Si} / \mathrm{TiO}_{2}$ core/shell NWs (cs-NWs) samples}

The cleaned Si NW samples (discussed above) were transferred to the ALD machine to deposit a thin $\mathrm{TiO}_{2}$ shell using the thermal $\mathrm{ALD}$ at a temperature of $300^{\circ} \mathrm{C}$ (Figure $\mathrm{S} 6$ and S7). The number of cycles was 682 giving a thickness of $\sim 30 \mathrm{~nm}$ on the Si film substrate. Note that the ALD growth rate is a little larger (not significant) at higher temperature of $300^{\circ} \mathrm{C}$, but we considered the same rate to calculate the thickness. For the $\mathrm{N}_{2}$ annealed cs-NW samples, they were annealed at a temperature of $450^{\circ} \mathrm{C}$ for $1 \mathrm{hr}$ under a $\mathrm{N}_{2}$ flow of $1000 \mathrm{scc} / \mathrm{min}$, similar condition to that mentioned for the $\mathrm{Si} / \mathrm{TiO}_{2} / \mathrm{N}-\mathrm{Fe}_{2} \mathrm{O}_{3}$ csh-NWs.

\subsection{Fabrication of $\mathrm{TiO}_{2} / \mathrm{TiO}_{2}$ cs-NTs photoanodes}

Highly ordered $\mathrm{TiO}_{2} \mathrm{NT}$ arrays were prepared by an anodization process in a two-electrode electrochemical bath. Ti foil (99.5\% purity, $0.25 \mathrm{~mm}$ thick, Alfa Aesar) and Ti mesh (80 mesh woven from $0.13 \mathrm{~mm}$ dia wire, Alfa Aesar) (working electrode (WE)) were cleaned in a mild detergent, rinsed with DI water and ultra-sonicated in acetone and ethanol for 5 mins in each solvent. Then, the Ti foil/Ti mesh was immersed in 1:18:81 HF: $\mathrm{HNO}_{3}: \mathrm{H}_{2} \mathrm{O}$ (volume ratio) for 2 mins, rinsed generously with DI water and ultra-sonicated in DI water for another 5 mins. They were then dried by $\mathrm{N}_{2}$ gas flow. A Pt foil was used as the counter electrode (CE). The voltage was applied by a DC power supply (Agilent, E3612A). A thin $\mathrm{TiO}_{2} \mathrm{NT}$ array layer was produced by anodizing the Ti foil/Ti mesh in a solution of ethylene glycol (99.8\%, JT Baker), containing $0.30 \%$ ammonium fluoride $\left(\mathrm{NH}_{4} \mathrm{~F}, 96 \%\right.$, Alfa Aesar) and $5 \% \mathrm{H}_{2} \mathrm{O}$, for $3.5 \mathrm{hrs}$ at $60 \mathrm{~V}$. A thin $\mathrm{TiO}_{2}$ shell was finally deposited on the $\mathrm{TiO}_{2} \mathrm{NTs}$ using the thermal ALD at a temperature of $300^{\circ} \mathrm{C}$ for 454 cycle numbers providing a thickness of $\sim 20 \mathrm{~nm}$ on the flat Si substrate. 


\subsection{Characterization}

The samples morphology was examined on a Philips XL30 field-emission environmental scanning electron microscope (ESEM) at an accelerating voltage of $10.0 \mathrm{kV}$. Energy-dispersive X-ray spectroscopy (EDS) and elemental mapping analyses were used to examine the materials composition. Crystal structures of samples were characterized using X-ray diffraction (XRD) by a Bruker D2 Phaser X-ray diffractometer with $\mathrm{Cu} K \alpha(\lambda=0.154 \mathrm{~nm})$ as the radiation source.

\subsection{PEC and IPCE measurements}

To evaluate the samples performance, they were bonded to coated $\mathrm{Cu}$ wire at the back using indium. For the Ti substrates, indium was also used to provide ohmic contact to Ti. The edges and backside of samples were sealed using Hysol 1C epoxy. For the mesh samples, only the contact area and edges were covered with epoxy. Current density measurements were performed in an aqueous solution of $0.25 \mathrm{M} \mathrm{Na}_{2} \mathrm{SO}_{4}$ buffered at $\mathrm{pH}=7.25$ or 7.1 with Phosphate Buffered Saline (PBS, Sigma) (DI water resistivity was $17.6-17.7$ or $18.2 \mathrm{M} \Omega-\mathrm{cm}$ for $\mathrm{pH}=7.25$ or 7.1, respectively) (neutral $\mathrm{pH}$ water) with a three- or two-electrode setup. The three-electrode setup includes sample as working electrode (WE), Pt mesh/foil as counter electrode (CE), and $\mathrm{Ag} / \mathrm{AgCl}(1 \mathrm{M} \mathrm{KCl})$ as reference electrode (RE). The two-electrode setup consists of sample as WE and Pt mesh/foil as CE. A light power intensity of $100 \mathrm{~mW} / \mathrm{cm}^{2}$ was tuned at the samples position using a Newport solar simulator with a xenon lamp equipped with a $1.5 \mathrm{AM}$ filter. The current density measurements were collected using a Digi-Ivy potentiostat. A scan rate of 10 $\mathrm{mV} / \mathrm{s}$ was used for the current density measurements (linear sweep voltammetry (LSV)). During the current density measurements, a mild agitation was employed and the electrolyte was constantly purged with a small flow of $\mathrm{N}_{2}$ gas. The applied potentials versus $\mathrm{Ag} / \mathrm{AgCl} \mathrm{RE}$ were 
converted to the potentials versus reversible hydrogen electrode (RHE) or normal hydrogen electrode (NHE) using the Nernst equation. The current densities here are calculated using the geometric areas. To test the full PEC system, consisting of the csh-NWs photocathode (set as WE) and the cs-NTs photoanode (set as CE) in a two-electrode setup, samples were put next to each other in a way that solar simulator can shine both samples. A monochromator (iHR 550) equipped with the solar simulator with the 1.5 AM filter as the light source was used to carry out the spectral photoresponse and incident photon-to-current efficiency (IPCE) measurements. The monochromatic light spectrum was calibrated by a silicon photodiode (Newport 818-UV). Spectral photoresponse and IPCE measurements were performed in the same three-electrode setup and electrolyte $\left(0.25 \mathrm{M} \mathrm{Na}_{2} \mathrm{SO}_{4}\right.$ buffered at $\left.\mathrm{pH}=7.25\right)$ as used for the current density measurements with $\mathrm{N}_{2}$ purging but without using agitation during the tests.

The solar-to-hydrogen (STH) efficiency is calculated using below equation considering $100 \%$ faradaic efficiency $[1,37]$

$\eta_{\mathrm{STH}}(\%)=\frac{100 J_{o p}(1.23 \mathrm{~V})}{P_{i n}}$

where $J_{o p}$ is the photocurrent density of crossing point between photocurrents of photocathode and photoanode, and $P_{\text {in }}$ is the incident light power density $\left(\mathrm{mW} / \mathrm{cm}^{2}\right.$ ) (which is $100 \mathrm{~mW} / \mathrm{cm}^{2}$ here). Note that we ignored any light attenuation, which may come from the PEC setup, resulting in not having exact $100 \mathrm{~mW} / \mathrm{cm}^{2}$ on the sample surface. For the PEC tandem cell (full PEC system), $J_{o p}$ is the photocurrent density at zero bias (short-circuit photocurrent density). 


\section{Results and Discussion}

Figure 1 shows a schematic representation of fabrication procedure for the photoelectrodes. Wafer-scale vertically ordered $\mathrm{p}-\mathrm{Si} \mathrm{NW}$ arrays/cores using $\mathrm{p}-\mathrm{Si}(100)$ wafer were first fabricated using an aqueous Ag-assisted electroless etching method, followed by coating of a thin ALD $\mathrm{TiO}_{2}$ layer served as a seeding layer for the $\beta-\mathrm{FeOOH}$ NRs growth, and finally $\beta-\mathrm{FeOOH}$ NRs were grown on the $\mathrm{TiO}_{2}$-coated $\mathrm{Si} \mathrm{NW}$ backbones using hydrothermal growth method. The $\beta$ $\mathrm{FeOOH}$ NRs were subsequently converted into the $\alpha-\mathrm{Fe}_{2} \mathrm{O}_{3}$ NRs by annealing the samples at $450^{\circ} \mathrm{C}$ in air (denoted as $\mathrm{A}-\mathrm{Fe}_{2} \mathrm{O}_{3}$ ) or under $\mathrm{N}_{2}$ atmosphere (denoted as $\mathrm{N}-\mathrm{Fe}_{2} \mathrm{O}_{3}$ ) for $1 \mathrm{hr}$. The fabricated 3D array structure is denoted as p-Si/TiO $/ 2-\mathrm{Fe}_{2} \mathrm{O}_{3}$ and $\mathrm{p}-\mathrm{Si} / \mathrm{TiO} \mathrm{O}_{2} / \mathrm{N}-\mathrm{Fe}_{2} \mathrm{O}_{3}$ csh-NWs for annealing in air and under $\mathrm{N}_{2}$ environment, respectively. Highly ordered $\mathrm{TiO}_{2} \mathrm{NT}$ arrays on $\mathrm{Ti}$ foil/mesh were prepared by an anodization process and subsequently, the $\mathrm{TiO}_{2} \mathrm{NTs}$ were coated with a thin ALD $\mathrm{TiO}_{2}$ layer to form $\mathrm{TiO}_{2} / \mathrm{TiO}_{2}$ cs-NTs. A PEC tandem cell was made using the csh-NWs as photocathode and the cs-NTs as photoanode.

Figure 2a-2d show scanning electron microscopy (SEM) images of $\mathrm{p}-\mathrm{Si} / \mathrm{TiO}_{2} / \mathrm{A}-\mathrm{Fe}_{2} \mathrm{O}_{3}$ cshNWs. The $\mathrm{Fe}_{2} \mathrm{O}_{3}$ NRs are polycrystalline (Figure 2a). Figure 2b shows that there are spaces between the csh-NWs, coming from good spaces between the etched Si NW cores (see Figure S1), in which water molecules can easily penetrate for water splitting reaction on the surface of csh-NWs. As shown in Figure 2c, the growth of $\mathrm{Fe}_{2} \mathrm{O}_{3}$ NRs is uniform through the entire length of tall Si NW backbones with $\sim 6.5 \mu$ m length (Figure S1) due to uniform coverage of $\mathrm{ALD} \mathrm{TiO}_{2}$ layer. The csh-NWs growth is also uniform within the whole area of samples (which can be evident by the low-magnification image in Figure 2d) revealing the potential of scaling up the electrodes. Note that we did not observe any significant morphological difference in the cshNWs with A- $\mathrm{Fe}_{2} \mathrm{O}_{3}$ and $\mathrm{N}-\mathrm{Fe}_{2} \mathrm{O}_{3}$ NRs suggesting that the $\mathrm{N}_{2}$ atmosphere did not significantly 
change the csh-NWs morphology. Also p-Si/TiO $/ 2-\mathrm{Fe}_{2} \mathrm{O}_{3}$ and p-Si/TiO $/ \mathrm{N}-\mathrm{Fe}_{2} \mathrm{O}_{3}$ csh-NWs showed similar XRD pattern indicating that there is no difference in their crystal structure. The A- $-\mathrm{Fe}_{2} \mathrm{O}_{3}$ and $\mathrm{N}-\mathrm{Fe}_{2} \mathrm{O}_{3}$ NRs grown directly on FTO substrate exhibit similar red color (see Figure S2), evident of successful transformation of $\beta-\mathrm{FeOOH}$ to $\alpha-\mathrm{Fe}_{2} \mathrm{O}_{3}$ for both cases, and this was also confirmed with the same XRD pattern for both samples. The Si NW cores in the p$\mathrm{Si} / \mathrm{TiO}_{2} / \mathrm{A}-\mathrm{Fe}_{2} \mathrm{O}_{3}$ csh-NWs cannot be oxidized during the annealing process under air because the $\mathrm{TiO}_{2}$ seeding layer is totally uniform (see Supporting Information) and transmission electron microscopy (TEM) characterization on a similar NW structure has shown no evidence of Si NW oxidation [38]. Elemental mapping analysis shown in Figure S3 confirms the materials composition of the csh-NWs.

Figure 2e-2h exhibit the SEM images of bare $\mathrm{TiO}_{2} \mathrm{NTs}$ and $\mathrm{TiO}_{2} / \mathrm{TiO}_{2}$ cs-NTs with an average top inner diameter of $97 \mathrm{~nm}$ and $57 \mathrm{~nm}$, respectively. The $\mathrm{TiO}_{2}$ shell can cover the entire length of long $\mathrm{TiO}_{2}$ NTs (see Figure $2 \mathrm{~g}$ and $2 \mathrm{~h}$ ) due to gas phase nature of ALD deposition. However, from the SEM images, it was hard to realize uniform coating of $\mathrm{ALD} \mathrm{TiO}_{2}$ for both inner and outer sidewalls of NTs along the whole NTs length. The XRD analyses (Figure 2i) show similar patterns for both bare $\mathrm{TiO}_{2} \mathrm{NTs}$ and $\mathrm{TiO}_{2} / \mathrm{TiO}_{2}$ cs-NTs revealing that both core and shell exhibit similar phase of anatase.

Figure 3a shows the current density of bare p-Si NWs, p-Si/TiO $/ 2-\mathrm{Fe}_{2} \mathrm{O}_{3}$ csh-NWs, and p$\mathrm{Si} / \mathrm{TiO}_{2} / \mathrm{N}-\mathrm{Fe}_{2} \mathrm{O}_{3}$ csh-NWs using a three-electrode setup in which all the samples show photocathodic behavior and there is no significant photoanodic current even at high biasing potentials of over $+1.5 \mathrm{~V}$ versus RHE. The $\mathrm{p}-\mathrm{Si} / \mathrm{TiO}_{2} / \mathrm{A}-\mathrm{Fe}_{2} \mathrm{O}_{3}$ csh-NWs offer much higher photocathodic current and significant onset potential shift toward positive potentials compared to the bare $\mathrm{p}-\mathrm{Si} \mathrm{NWs}$, leading to an onset potential of about $+0.38 \mathrm{~V}$ versus RHE, a photocurrent of 
about $-0.4 \mathrm{~mA} / \mathrm{cm}^{2}$ at $0 \mathrm{~V}$ versus RHE (see Figure $3 \mathrm{a}$ ), and a photocurrent of about -0.43 $\mathrm{mA} / \mathrm{cm}^{2}$ at the water reduction potential (see Figure S4). Note that the onset potential is calculated when the net photocurrent (light current - dark current) reaches a value of -0.1 $\mathrm{mA} / \mathrm{cm}^{2}$. The significantly enhanced photocathodic performance is attributed to the increased reaction surface area which is evident from the SEM images, effective energy band alignment among p-Si, $\mathrm{n}-\mathrm{TiO}_{2}$ and $\mathrm{n}-\mathrm{Fe}_{2} \mathrm{O}_{3}$ enhancing the charge separation (see Figure S5), improved optical absorption $[18,36]$, and increased gas evolution coming from the $1 \mathrm{D}$ nature of our $\mathrm{Fe}_{2} \mathrm{O}_{3}$ NRs [39]. The morphology and PEC performance of p-Si/TiO 2 cs-NWs are shown in Figure S6 and $\mathrm{S} 7$ revealing the uniform coating of $\mathrm{ALD} \mathrm{TiO}_{2}$ shell and its contribution in the enhanced performance. It is worth noting that the stability of the $\mathrm{Fe}_{2} \mathrm{O}_{3}$-coated p-Si photocathodes has been investigated elsewhere to rule out effect from $\mathrm{Fe}_{2} \mathrm{O}_{3}$ dissolution which may contribute to the $J-V$ measurements [38]. The csh-NWs performance further improves by $\mathrm{N}_{2}$ annealing (using $\mathrm{N}$ $\mathrm{Fe}_{2} \mathrm{O}_{3}$ instead of $\left.\mathrm{A}-\mathrm{Fe}_{2} \mathrm{O}_{3}\right)$ resulting in an onset potential of about $+0.46 \mathrm{~V}$ versus RHE, a photocurrent of about $-0.55 \mathrm{~mA} / \mathrm{cm}^{2}$ at $0 \mathrm{~V}$ versus RHE (see Figure 3a), and a photocurrent of about $-0.61 \mathrm{~mA} / \mathrm{cm}^{2}$ at the water reduction potential (see Figure S4). The performance improvement can be mainly due to superior conductivity of $\mathrm{Fe}_{2} \mathrm{O}_{3}$ NRs $[40,41]$ resulting in an enhanced collection efficiency of photoexcited electrons. Annealing under $\mathrm{N}_{2}$ atmosphere can also enhance the conductivity of $\mathrm{TiO}_{2}$ seeding layer assisting the performance enhancement (see Figure S7). However, annealing at $450^{\circ} \mathrm{C}$ under the applied $\mathrm{N}_{2}$ atmosphere condition may not change appreciably the band gap of $\mathrm{Fe}_{2} \mathrm{O}_{3}$ (as can be deduced from the optical images in Figure $\mathrm{S} 2$ ) or $\mathrm{TiO}_{2}$ (no noticeable color change was observed after annealing). The $\mathrm{N}-\mathrm{Fe}_{2} \mathrm{O}_{3} \mathrm{NRs}$ grown on the FTO substrate also showed improved photoanodic performance than $\mathrm{A}-\mathrm{Fe}_{2} \mathrm{O}_{3} \mathrm{NRs}$ (data not shown here) further confirming the improved conductivity which is consistent with the 
reported observation elsewhere [40]. The current density measurements of the corresponding samples using a two-electrode PEC setup in Figure $3 \mathrm{~b}$ exhibit similar trend for photocurrents as that observed with a three-electrode setup in Figure 3a. The p-Si/TiO $/ 2-\mathrm{Ne}_{2} \mathrm{O}_{3}$ csh-NWs also exhibit high IPCEs in a wide range (see Figure S8).

The achieved performance facilitates to obtain a full PEC device for overall spontaneous solar water splitting in the neutral $\mathrm{pH}$ water. To make the PEC tandem cell for overall solar water splitting, we used $\mathrm{TiO}_{2} \mathrm{NT}$ array as a model for the photoanode since it can provide a low onset potential. However, the bare $\mathrm{TiO}_{2}$ NT sample cannot provide a high photoanodic current due to $\mathrm{TiO}_{2}$ poor properties $\left[42,43\right.$, and its onset potential needs to be further reduced. The $\mathrm{TiO}_{2} \mathrm{NTs}$ were then coated with a thin ALD $\mathrm{TiO}_{2}$ layer forming $\mathrm{TiO}_{2} / \mathrm{TiO}_{2}$ cs-NTs to achieve a higher photoanodic current (data not shown here). The enhanced photoanodic current can be due to passivation of surface states $[44,45]$ and improved reaction surface area. The surface of ALD $\mathrm{TiO}_{2}$ coating is not smooth (see Figure S9) meaning that the shell coating provides more junction area. As mentioned above, both $\mathrm{TiO}_{2}$ core and shell are anatase phase, thus there is no junction barrier between core and shell to block the charge transfer. The photoanodic current of the $\mathrm{TiO}_{2} / \mathrm{TiO}_{2}$ cs-NTs grown on $\mathrm{Ti}$ foil in the neutral $\mathrm{pH}$ water is shown in Figure $4 \mathrm{a}$ along with the photocathodic current of $\mathrm{p}-\mathrm{Si} / \mathrm{TiO}_{2} / \mathrm{N}-\mathrm{Fe}_{2} \mathrm{O}_{3}$ csh-NWs to determine the crossing point between the $J$ - $V$ curves. The photocurrents intersection is at $\sim 0.42 \mathrm{~V}$ versus RHE with a photocurrent density of $\sim 0.17 \mathrm{~mA} / \mathrm{cm}^{2}$, resulting in a STH efficiency of $\sim 0.21 \%$. Using $\mathrm{TiO}_{2} / \mathrm{TiO}_{2}$ cs-NTs grown on Ti mesh instead of Ti foil, the photoanodic performance improves (Figure 4a inset) in which the photocurrents cross each other at $\sim 0.3 \mathrm{~V}$ versus RHE with a photocurrent density of $\sim 0.3 \mathrm{~mA} / \mathrm{cm}^{2}$ leading to a STH efficiency of $\sim 0.37 \%$, due to enhanced reaction surface area 
coming from the mesh substrate. To illuminate both sides of the mesh sample during the current density measurement, the glass PEC cell was covered with a piece of aluminium foil.

The achieved performances reveal the fact that the developed photoelectrodes can run overall solar water splitting. To figure out this feasibility, a full PEC system made of these two photoelectrodes were tested in a way that the csh-NWs photocathode was set as WE and the csNTs (grown on Ti foil) photoanode was set as CE in a two-electrode setup. The current density of full system is shown in Figure $4 \mathrm{~b}$ exhibiting the operation of full system in the neutral $\mathrm{pH}$ water with a non-zero photocurrent density of $\sim 0.15 \mathrm{~mA} / \mathrm{cm}^{2}$ at zero bias, which leads to a STH efficiency of $\sim 0.18 \%$. Note that the photocurrent density of full system at zero bias $(\sim 0.15$ $\left.\mathrm{mA} / \mathrm{cm}^{2}\right)$ is a little smaller than the photocurrent density at the crossing point $\left(\sim 0.17 \mathrm{~mA} / \mathrm{cm}^{2}\right)$ which results in a slightly lower efficiency. The obtained performance is promising considering several factors; (i) performance was assessed in a neutral solution with a low morality of 0.25 , (ii) all photoelectrodes were fabricated using earth-abundant materials with cheap fabrication processes except for ALD which may be replaced with another fabrication technique, and (iii) there is no catalyst loaded on the electrodes. To obtain a high STH efficiency in such a full system, a catalyst (preferably bifunctional) working in neutral or near-neutral $\mathrm{pH}$ water toward basic solution such as $\mathrm{NiO}[36,46,47]$ can be added to both photoelectrodes. Additionally, a different or composite photoanode material whose absorption is matched to the solar spectrum, has a low onset potential, and is stable can be used to substantially improve the STH efficiency beyond that achieved in this study. 


\section{Conclusions}

In summary, we demonstrated the fabrication and characterization of a novel PEC tandem cell, consisting of $\mathrm{p}-\mathrm{Si} / \mathrm{TiO}_{2} / \mathrm{Fe}_{2} \mathrm{O}_{3}$ csh-NW array photocathode and $\mathrm{TiO}_{2} / \mathrm{TiO}_{2}$ cs-NT array photoanode, for overall solar water splitting in the neutral $\mathrm{pH}$ water. The csh-NWs, made mostly from solution growth methods, exhibited considerably improved photocathodic performance in the neutral $\mathrm{pH}$ water with positive onset potentials of about $+0.38 \mathrm{~V}$ and $+0.46 \mathrm{~V}$ versus RHE, and photocurrents of about $-0.4 \mathrm{~mA} / \mathrm{cm}^{2}$ and $-0.55 \mathrm{~mA} / \mathrm{cm}^{2}$ at $0 \mathrm{~V}$ versus RHE for the unmodified and $\mathrm{N}$-modified $\mathrm{Fe}_{2} \mathrm{O}_{3} \mathrm{NRs}$, respectively. The PEC tandem cell was finally shown to handle overall solar neutral water splitting with a STH efficiency of $\sim 0.18 \%$. The obtained results reveal promising potential of making PEC tandem cells using earth-abundant materials with low cost processes for solar hydrogen fuel production.

\section{Acknowledgments}

This work was supported by the National Science Foundation (NSF CBET1236155) and the Iwama Endowed Fund at UCSD. A.K. thanks UCSD Nano3 cleanroom personnel for their support and assistance. 


\section{References}

[1] M. G. Walter, E. L. Warren, J. R. McKone, S. W. Boettcher, Q. Mi, E. A. Santori, et al., Chem. Rev. 110 (2010) 6446-6473.

[2] M. J. Kenney, M. Gong, Y. Li, J. Z. Wu, J. Feng, M. Lanza, et al., Science 342 (2013) 836-840.

[3] S. Y. Reece, J. A. Hamel, K. Sung, T. D. Jarvi, A. J. Esswein, J. J. H. Pijpers, et al., Science 334 (2011) 645-648.

[4] C. Liu, J. Tang, H. M. Chen, B. Liu, and P. Yang, Nano Lett. 13 (2013) 2989-2992.

[5] O. Khaselev and J. A. Turner, Science 280 (1998) 425-427.

[6] J. Luo, J.-H. Im, M. T. Mayer, M. Schreier, M. K. Nazeeruddin, N.-G. Park, et al., Science 345 (2014) 1593-1596.

[7] G. Wang, H. Wang, Y. Ling, Y. Tang, X. Yang, R. C. Fitzmorris, et al., Nano Lett. 11 (2011) 3026-3033.

[8] X. Shi, K. Zhang, K. Shin, M. Ma, J. Kwon, I. T. Choi, et al., Nano Energy 13 (2015) 182-191.

[9] S. Hu, C. Xiang, S. Haussener, A. D. Berger, and N. S. Lewis, Energy Environ. Sci. 6 (2013) 2984-2993.

[10] J. W. Ager, M. Shaner, K. Walczak, I. D. Sharp, and S. Ardo, Energy Environ. Sci., 8 (2015) 2811-2824.

[11] S. Hu, M. R. Shaner, J. A. Beardslee, M. Lichterman, B. S. Brunschwig, and N. S. Lewis, Science 344 (2014) 1005-1009.

[12] Y. W. Chen, J. D. Prange, S. Dühnen, Y. Park, M. Gunji, C. E. D. Chidsey, et al., Nat. Mater. 10 (2011) 539-544.

[13] A. Paracchino, V. Laporte, K. Sivula, M. Grätzel, and E. Thimsen, Nat. Mater. 10 (2011) 456-461.

[14] M. H. Lee, K. Takei, J. Zhang, R. Kapadia, M. Zheng, Y.-Z. Chen, et al., Angew. Chem. Int. Ed. 124 (2012) 10918-10922.

[15] S. C. Warren, K. Voïtchovsky, H. Dotan, C. M. Leroy, M. Cornuz, F. Stellacci, et al., Nat. Mater. 12 (2013) 842-849.

[16] H.-P. Wang, K. Sun, S. Y. Noh, A. Kargar, M.-L. Tsai, M.-Y. Huang, et al., Nano Lett. 15 (2015) 2817-2824.

[17] S. W. Boettcher, J. M. Spurgeon, M. C. Putnam, E. L. Warren, D. B. Turner-Evans, M. D. Kelzenberg, et al., Science 327 (2010) 185 185-187.

[18] M. T. Mayer, C. Du, and D. Wang, J. Am. Chem. Soc. 134 (2012) 12406-12409.

[19] N. P. Dasgupta, C. Liu, S. Andrews, F. B. Prinz, and P. Yang, J. Am. Chem. Soc. 135 (2013) 12932-12935.

[20] J. D. Benck, S. C. Lee, K. D. Fong, J. Kibsgaard, R. Sinclair, and T. F. Jaramillo, Adv. Energy Mater. 4 (2014) 1400739.

[21] Q. Ding, F. Meng, C. R. English, M. Cabán-Acevedo, M. J. Shearer, D. Liang, et al., J. Am. Chem. Soc. 136 (2014) 8504-8507.

[22] S. Chandrasekaran, T. Nann, and N. H. Voelcker, Nano Energy 17 (2015) 308-322.

[23] X.-Q. Bao, D. Y. Petrovykh, P. Alpuim, D. G. Stroppa, N. Guldris, H. Fonseca, et al., Nano Energy 16 (2015) 130-142.

[24] T. Zhu and M. N. Chong, Nano Energy 12 (2015) 347-373. 
[25] G. K. Mor, O. K. Varghese, R. H. T. Wilke, S. Sharma, K. Shankar, T. J. Latempa, et al., Nano Lett. 8 (2008) 1906-1911.

[26] Y. J. Hwang, A. Boukai, and P. Yang, Nano Lett. 9 (2008) 410-415.

[27] M. R. Shaner, K. T. Fountaine, S. Ardo, R. H. Coridan, H. A. Atwater, and N. S. Lewis, Energy Environ. Sci. 7 (2014) 779-790.

[28] J. Yang, K. Walczak, E. Anzenberg, F. M. Toma, G. Yuan, J. Beeman, et al., J. Am. Chem. Soc. 136 (2014) 6191-6194.

[29] J. Shi, Y. Hara, C. Sun, M. A. Anderson, and X. Wang, Nano Lett. 11 (2011) 3413-3419.

[30] A. Kargar, K. Sun, Y. Jing, C. Choi, H. Jeong, Y. Zhou, et al., Nano Lett. 13 (2013) 3017-3022.

[31] X. Wang, K.-Q. Peng, Y. Hu, F.-Q. Zhang, B. Hu, L. Li, et al., Nano Lett. 14 (2014) 1823.

[32] S. Y. Noh, K. Sun, C. Choi, M. Niu, M. Yang, K. Xu, et al., Nano Energy 2 (2013) 351360.

[33] K. Jun, Y. S. Lee, T. Buonassisi, and J. M. Jacobson, Angew. Chem. Int. Ed. 51 (2012) 423-427.

[34] A. Kargar, K. Sun, S. J. Kim, D. Lu, Y. Jing, Z. Liu, et al., Phys. Status Solidi A 210 (2013) 2561-2568.

[35] L. Vayssieres, N. Beermann, S.-E. Lindquist, and A. Hagfeldt, Chem. Mater. 13 (2001) 233-235.

[36] A. Kargar, J. S. Cheung, C.-H. Liu, T. K. Kim, C. T. Riley, S. Shen, et al., Nanoscale 7 (2015) 4900-4905.

[37] Z. Chen, T. F. Jaramillo, T. G. Deutsch, A. Kleiman-Shwarsctein, A. J. Forman, N. Gaillard, et al., J. Mater. Res. 25 (2010) 3-16.

[38] A. Kargar, S. J. Kim, P. Allameh, C. Choi, N. Park, H. Jeong, et al., Adv. Funct. Mater. 25 (2015) 2609-2615.

[39] K. Sun, Y. Jing, C. Li, X. Zhang, R. Aguinaldo, A. Kargar, et al., Nanoscale, 4 (2012) 1515-1521.

[40] Y. Ling, G. Wang, J. Reddy, C. Wang, J. Z. Zhang, and Y. Li, Angew. Chem. Int. Ed. 51 (2012) 4074-4079.

[41] X. Lu, Y. Zeng, M. Yu, T. Zhai, C. Liang, S. Xie, et al., Adv. Mater. 26 (2014) 31483155.

[42] A. L. Linsebigler, G. Lu, and J. T. Yates, Chem. Rev. 95 (1995) 735-758.

[43] E. Hendry, M. Koeberg, B. O'Regan, and M. Bonn, Nano Lett. 6 (2006) 755-759.

[44] F. Le Formal, N. Tetreault, M. Cornuz, T. Moehl, M. Gratzel, and K. Sivula, Chem. Sci. 2 (2011) 737-743.

[45] Y. J. Hwang, C. Hahn, B. Liu, and P. Yang, ACS Nano 6 (2012) 5060-5069.

[46] M. Gong, W. Zhou, M.-C. Tsai, J. Zhou, M. Guan, M.-C. Lin, et al., Nat. Commun. 5 (2014) 4695.

[47] L. Trotochaud, J. K. Ranney, K. N. Williams, and S. W. Boettcher, J. Am. Chem. Soc. 134 (2012) 17253-17261. 


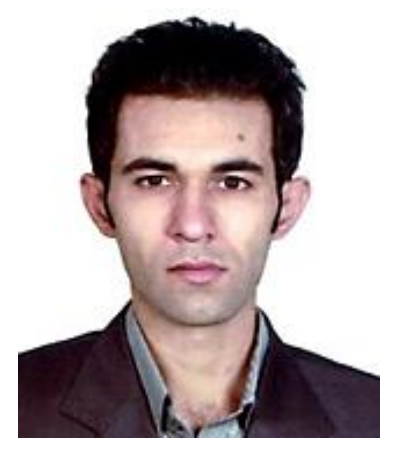

Alireza Kargar is a $\mathrm{PhD}$ candidate in the Electrical and Computer Engineering Department of the University of California, San Diego. He received the B.S. degree from Shiraz University, Shiraz, Iran. His current research interests are design and fabrication of different nanostructures for solar energy conversion devices with focus on solar fuel generation systems.

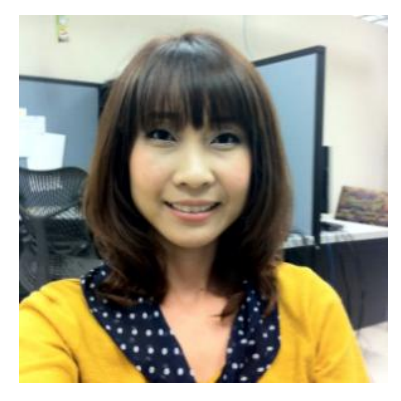

Jirapon Khamwannah received her PhD degree (2015) in Materials Science and Engineering from University of California, San Diego. She is currently a lecturer at Chulalongkorn University, Thailand. Her research mainly focuses on advanced nanostructure materials and 3-D structure for applications in Dye-sensitized solar cells.

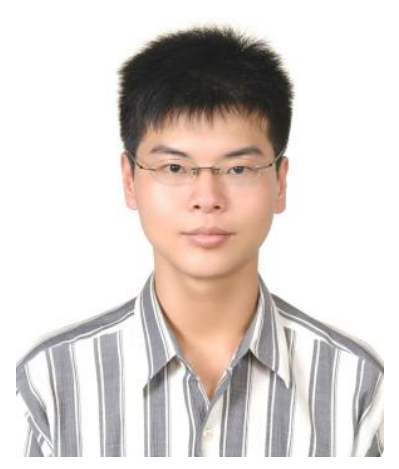

Chin-Hung Liu is a Ph.D. in the Materials Science and Engineering Program at University of California, San Diego (UCSD). He obtained M.S. degree from National Tsing Hua University (Taiwan, R.O.C.) and Bachelor degree from National Cheng Kung University (Taiwan, R.O.C.). 
His research topics include on magnetic materials, energy materials, packaging materials and IIIV semiconductors.

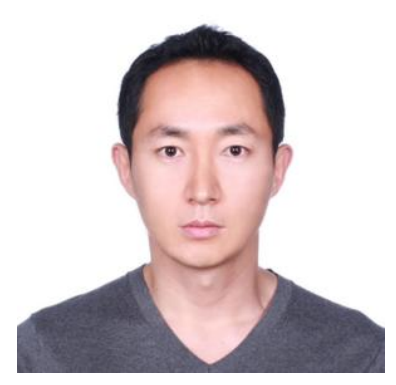

Namseok Park received a B.S. degree in electrical engineering from Inha University, Incheon, South Korea in 2004 and M.S. and Ph.D. degrees from the University of California, San Diego in electrical engineering (Applied Physics) in 2010 and 2015, respectively. His works included synthesis and optoelectronic devices of wide bandgap semiconducting metal oxide thin films and development of process integration of wearable Si MOSFET circuits.

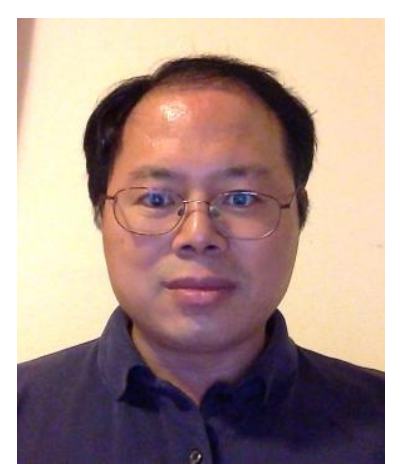

Deli Wang received his B.S. in Polymer Chemistry and Ph.D. in Material Science from the University of Science and Technology of China in 1990 and the University of California at Santa Barbara in 2001, respectively. He then worked as a postdoctoral researcher at Harvard University on semiconductor nanowires and nanoelectronics. From 2004 to 2014, he was an assistant/associate professor in the Electrical and Computer Engineering department at the University of California - San Diego. Since 2014, Deli has been working at NEEM Scientific Inc, a startup company he founded. His interests include nanotechnology, sensors, optoelectronics, clean energy, and digital health. 


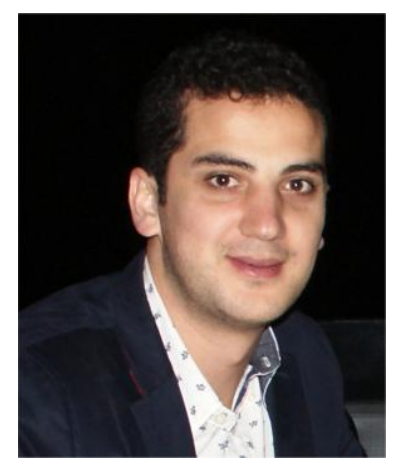

Shadi Dayeh received his PhD in Electrical Engineering from UC San Diego in 2008 followed by postdoctoral training at Los Alamos National Laboratory. He joined the faculty of ECE at UCSD in November 2012 where he directs the Integrated Electronics and Biointerfaces Laboratory.

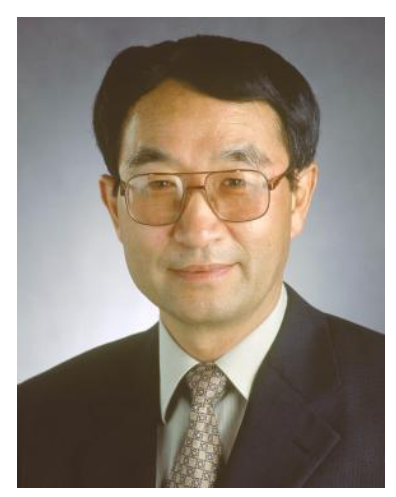

Dr. Sungho Jin received his Ph.D. in Materials Science \& Engineering from UC Berkeley in 1974. After joining Bell Labs at Murray Hill, NJ, he carried out forefront materials research for 26 years until he joined UC San Diego in 2002. As Distinguished Professor and Iwama Endowed Chair, he also served as Director, UCSD-wide Materials Science \& Engineering Program for the past 13 years. He is a member of the US National Academy of Engineering, Fellow of APS, TMS, and MRS, and Professor Emeritus of UCSD. He received various awards including John Bardeen Award and Albert-Sauveur Achievement Award. 


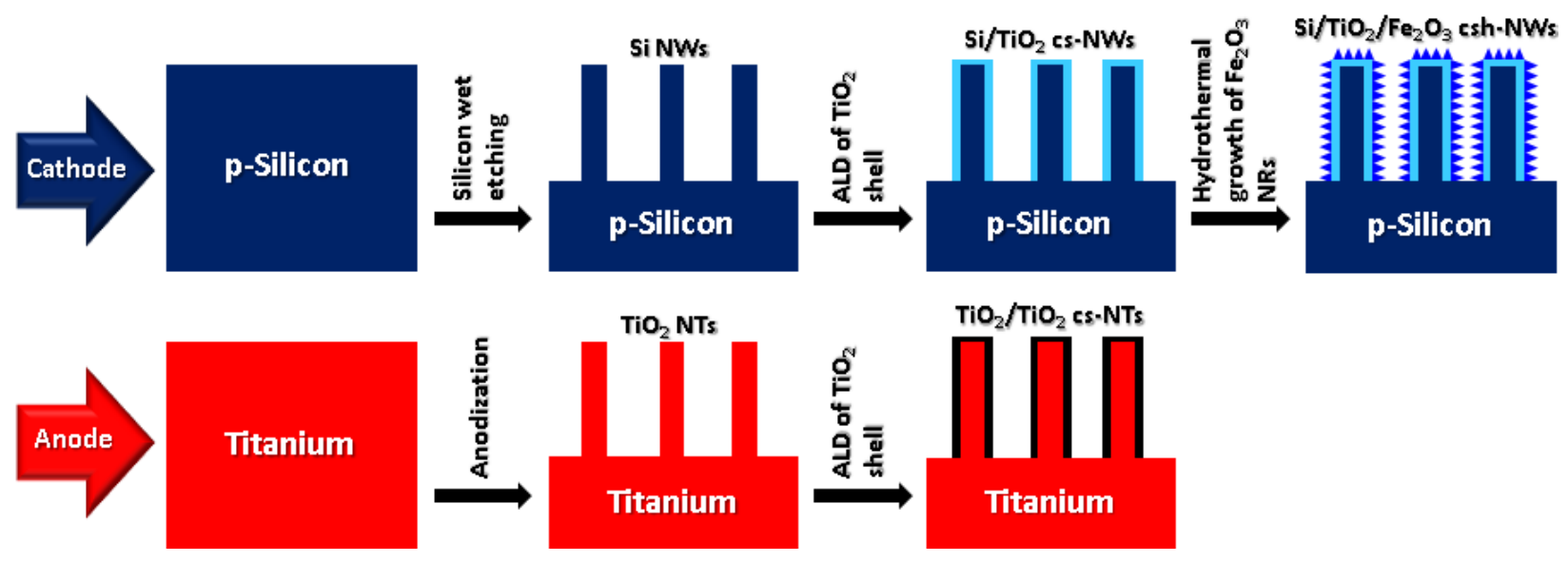

Figure 1. Schematic representation of fabrication procedure for the csh-NWs photocathode (top row) and the cs-NTs photoanode (bottom row). 

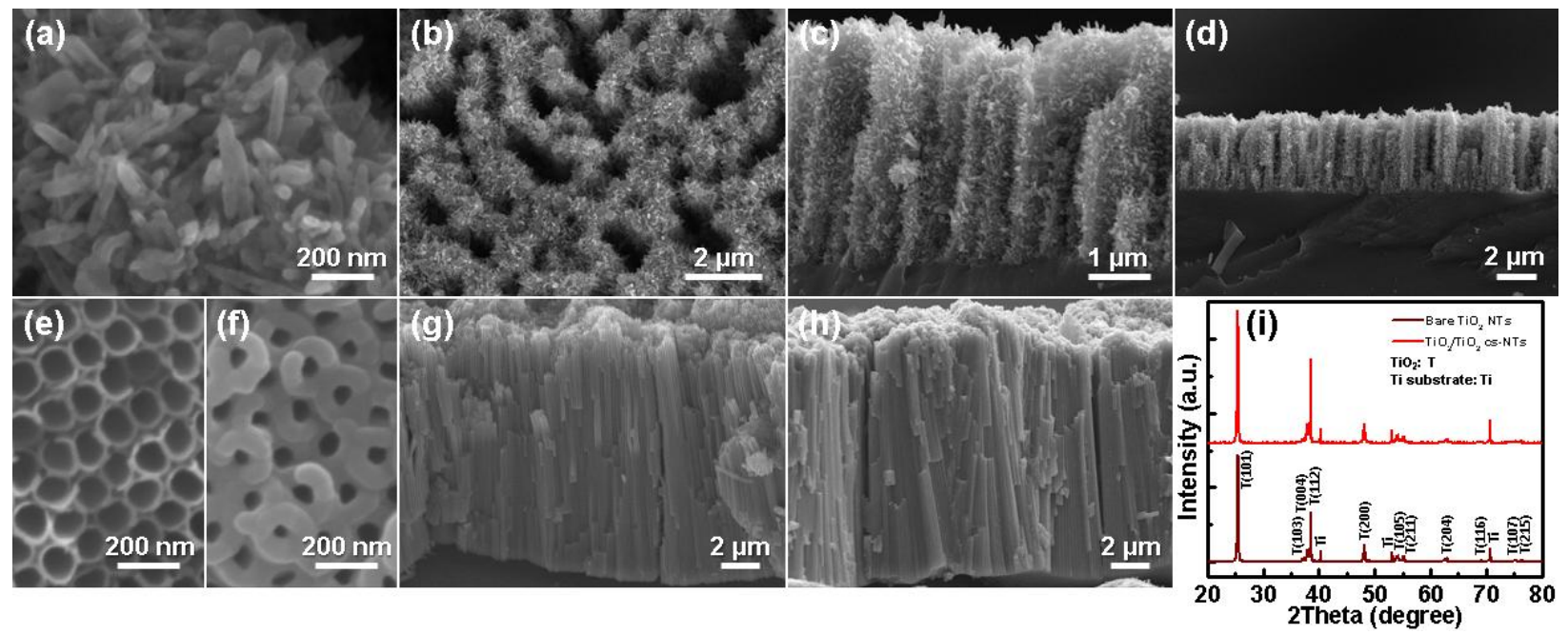

Figure 2. $(\mathrm{a}, \mathrm{b})$ Top-view (different magnification) and $(\mathrm{c}, \mathrm{d})$ cross-sectional view (different magnification) SEM images of $\mathrm{p}-\mathrm{Si} / \mathrm{TiO}_{2} / \mathrm{A}-\mathrm{Fe}_{2} \mathrm{O}_{3}$ csh-NW array. Top-view SEM images of (e) bare $\mathrm{TiO}_{2} \mathrm{NTs}$ and (f) $\mathrm{TiO}_{2} / \mathrm{TiO}_{2}$ cs-NTs. Tilted cross-sectional SEM images of (g) bare $\mathrm{TiO}_{2}$ NTs and (h) $\mathrm{TiO}_{2} / \mathrm{TiO}_{2}$ cs-NTs. Note that the tilted angle for (g) and (h) is not the same. (i) XRD patterns of bare $\mathrm{TiO}_{2} \mathrm{NTs}$ and $\mathrm{TiO}_{2} / \mathrm{TiO}_{2}$ cs-NTs. All $\mathrm{TiO}_{2} \mathrm{NTs}$ here are from those grown on $\mathrm{Ti}$ foil. 

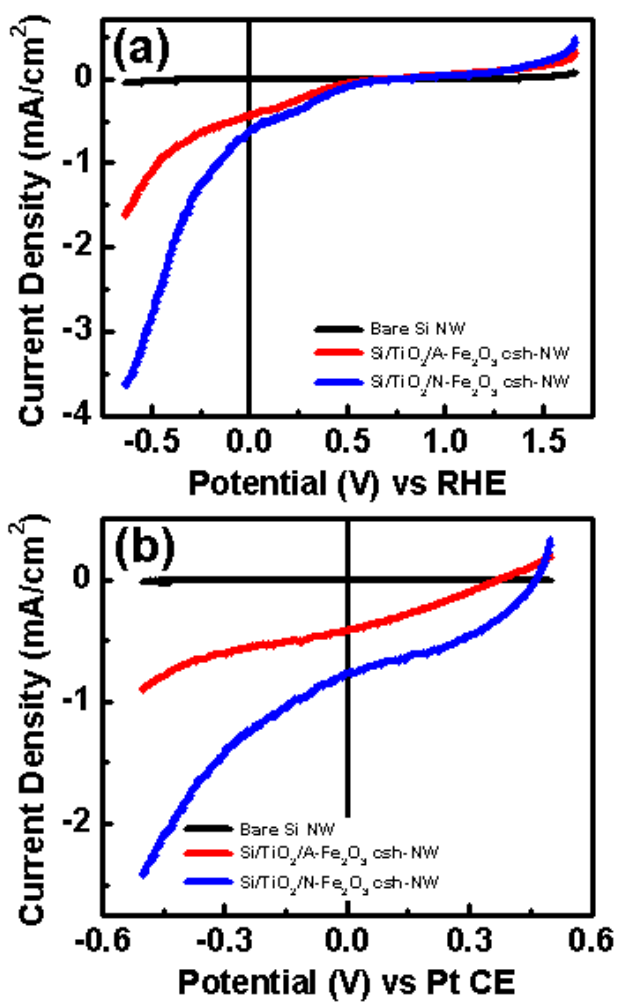

Figure 3. Current density under illumination of bare p-Si NW, p-Si/TiO $/ 2 / A-\mathrm{Fe}_{2} \mathrm{O}_{3}$ csh-NW, and $\mathrm{p}-\mathrm{Si} / \mathrm{TiO}_{2} / \mathrm{N}-\mathrm{Fe}_{2} \mathrm{O}_{3}$ csh-NW arrays measured in the neutral $\mathrm{pH}$ water using (a) a three-electrode and (b) a two-electrode PEC setups. 

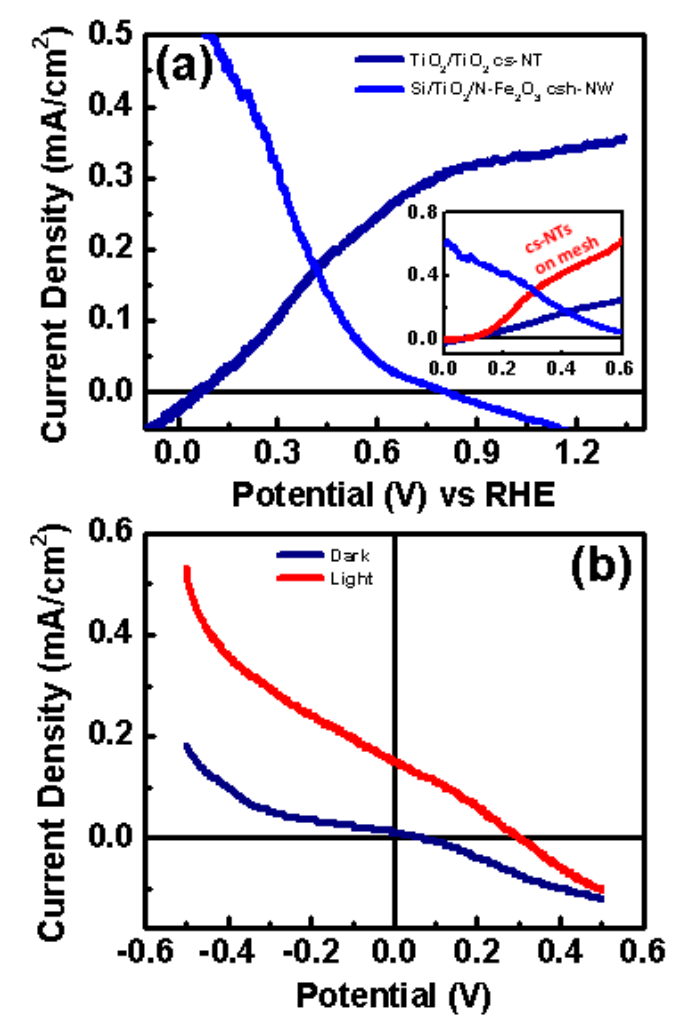

Figure 4. (a) Current density under illumination of $\mathrm{TiO}_{2} / \mathrm{TiO}_{2}$ cs-NTs (grown on foil) photoanode along with the current density under illumination of $\mathrm{p}-\mathrm{Si} / \mathrm{TiO} / \mathrm{N}-\mathrm{Fe}_{2} \mathrm{O}_{3}$ csh-NWs photocathode measured in the neutral $\mathrm{pH}$ water. Note that in this figure, the absolute value of current density for the csh-NWs is plotted. Inset shows the zoomed-in currents of the corresponding samples along with the current density under illumination of $\mathrm{TiO}_{2} / \mathrm{TiO}_{2}$ cs-NTs grown on mesh. (b) Current density at dark and under illumination of full PEC system, consisting of csh-NWs photocathode and $\mathrm{TiO}_{2} / \mathrm{TiO}_{2}$ cs-NTs (grown on foil) photoanode, tested in the neutral $\mathrm{pH}$ water. 


\section{Graphical abstract}

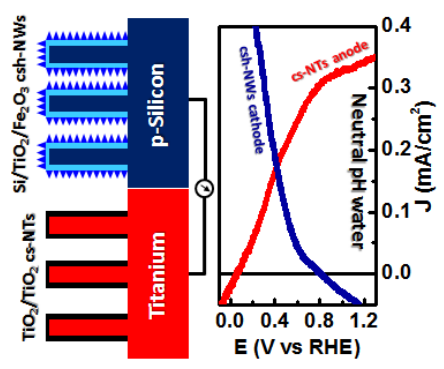

